\section{Public Health} Genomics
Public Health Genomics 2017;20:36-45

DOI: $10.1159 / 000455006$
Received: September 9, 2016

Accepted: December 8, 2016

Published online: January 10, 2017

\title{
Direct-to-Consumer Genetic Testing: User Motivations, Decision Making, and Perceived Utility of Results
}

\author{
J. Scott Roberts ${ }^{a}$ Michele C. Gornick ${ }^{b}$ Deanna Alexis Carere ${ }^{c}$ \\ Wendy R. Uhlmann ${ }^{b, d}$ Mack T. Ruffin ${ }^{\text {e Robert C. Green }}{ }^{f}$ \\ a Department of Health Behavior \& Health Education, University of Michigan School of Public Health, and \\ ${ }^{b}$ Department of Internal Medicine, University of Michigan Medical School, Ann Arbor, MI, USA; ' Department of \\ Pathology \& Molecular Medicine, McMaster University, Hamilton, ON, Canada; ${ }^{d}$ Department of Human Genetics, \\ University of Michigan Medical School, Ann Arbor, MI, e Department of Family and Community Medicine, \\ Penn State Health Milton S. Hershey Medical Center, Hershey, PA, and ${ }^{\mathrm{f}}$ Department of Medicine (Division of \\ Genetics), Brigham \& Women's Hospital, Harvard Medical School, Boston, MA, USA
}

\section{Key Words}

Direct-to-consumer genomic testing · Genetic testing . Health policy $\cdot$ Personal genomics $\cdot$ Test utility

\begin{abstract}
Background/Aims: To describe the interests, decision making, and responses of consumers of direct-to-consumer personal genomic testing (DTC-PGT) services. Methods: Prior to 2013 regulatory restrictions on DTC-PGT services, 1,648 consumers from 2 leading companies completed Web surveys before and after receiving test results. Results: Prior to testing, DTC-PGT consumers were as interested in ancestry (74\% very interested) and trait information (72\%) as they were in disease risks (72\%). Among disease risks, heart disease (68\% very interested), breast cancer (67\%), and Alzheimer disease $(66 \%)$ were of greatest interest prior to testing. Interest in disease risks was associated with female gender and poorer self-reported health $(p<0.01)$. Many consumers $(38 \%)$ did not consider the possibility of unwanted information before purchasing services; this group was more likely to be older,
\end{abstract}

\section{KARGER}

(C) 2017 S. Karger AG, Basel

E-Mail karger@karger.com

www.karger.com/phg male, and less educated $(p<0.05)$. After receiving results, $59 \%$ of respondents said test information would influence management of their health; $2 \%$ reported regret about seeking testing and $1 \%$ reported harm from results. Conclusion: DTC-PGT has attracted controversy because of the healthrelated information it provides, but nonmedical information is of equal or greater interest to consumers. Although many consumers did not fully consider potential risks prior to testing, DTC-PGT was generally perceived as useful in informing future health decisions.

(c) 2017 S. Karger AG, Basel

\section{Introduction}

The direct-to-consumer (DTC) offering of personal genomic testing (PGT) has generated controversy ever since its introduction, with concerns raised about its potential harms and limitations [1]. Such concerns often relate to the fact that DTC-PGT services are typically provided without a medical intermediary (e.g., an ordering

J. Scott Roberts, $\mathrm{PhD}$

University of Michigan School of Public Health

109 S. Observatory

Ann Arbor, MI 48109 (USA)

E-Mail jscottr@umich.edu 
physician or genetic counselor), and the types of tests offered (e.g., susceptibility tests for common diseases) are neither available in genetics clinics nor considered standard of care. Advocates of a DTC approach view regulatory restrictions based on such concerns as unwarranted paternalism [2], and they point to the potential of DTCPGT to expand access to personal health information, inform future plans, and motivate disease prevention efforts [3]. Many professional organizations, however, have criticized the validity and utility of the health-related information provided and expressed concerns about negative downstream consequences should consumers or their health-care providers misinterpret such information [4-6]. The US Food and Drug Administration (FDA)'s November 2013 warning letter to one major provider of PGT services noted concerns about the disclosure of pharmacogenomic and BRCA 1/2 mutation results in particular [7], and this action resulted in the temporary discontinuation of this company's marketing of services, as well as a reduction in the types of genetic tests offered. Reactions were mixed, with medical and public health experts generally applauding the intervention [8], while some academic commentators viewed the FDA action as regulatory overreach [9].

There is one area, however, where stakeholders on both sides of the debate are generally in agreement. That is, more data on the experience of PGT consumers could illuminate future practice and policy. A recent review of empirical studies in this area was conducted that included 39 articles representing (1) content analyses of DTC-PGT websites, (2) studies of consumer perspectives and experiences (e.g., test motivations and interests, comprehension of test results, psychological and behavioral impact of testing), and (3) studies of health-care provider perspectives (e.g., genetic counselors, primary care physicians) [10]. The review concluded that neither the health benefits envisioned by DTC-PGT proponents (e.g., significant improvements in positive health behaviors) nor the worst fears expressed by its critics (e.g., widespread psychological harms and misunderstanding of test results, undue burden on the health-care system from unnecessary clinical follow-up) have materialized to date. However, the review also noted that extant research in this area has significant limitations. For example, some studies have examined responses to hypothetical instead of actual PGT scenarios or provision of PGT information in a controlled research context, as opposed to consumer services available on the open market $[11,12]$. Studies have also been limited by low response rates, small sample sizes, an absence of data collection at baseline (i.e., prior

User Responses to DTC Genetic Testing to receiving one's test results), and/or an inability to link participants' responses to their actual genetic testing results [13].

To help address these gaps in the literature, we initiated the Impact of Personal Genomics Study (PGen). This longitudinal survey of consumers of 2 PGT companies examines respondents' appraisal of DTC-PGT services and their responses to their own personalized test results $[14,15]$. In an effort to inform practice and policy in this contentious area of personal genomics, the goals of this study include better understanding of (1) who obtains DTC-PGT, (2) how they decide to seek such services, and (3) what benefits, harms, and limitations they perceive in DTC-PGT after undergoing testing. In this analysis, we address the following specific questions: What are the demographic and health-related characteristics of PGT consumers? What motivations do they cite for seeking such services, and what factors do they consider (or not) in their test decisions? Finally, how useful do they find this information and in what ways?

\section{Materials and Methods}

Participants and Procedures

Detailed description of the PGen Study methods can be found elsewhere [16], with a brief summary provided here. Study participants were new customers of 23 andMe, Inc. (23andMe) and Pathway Genomics Corporation (Pathway) enrolled between March and July 2012. Throughout this period of data collection, 23andMe provided PGT services via a DTC model, disclosing a much wider range of genetic disease risk and pharmacogenomic information than currently offered in their services. A total of 3,900 new 23andMe customers received an e-mail from the company that included an overview of the study and an invitation to participate in the longitudinal set of PGen surveys.

Just prior to the start of data collection for the PGen Study, Pathway Genomics shifted from a DTC to a physician-mediated approach, whereby its services were still advertised online, but the company now required the consumer's physician to both order and return the results of testing. To ensure all PGen survey participants were reporting on a DTC-PGT experience, a modified service model was created for the purposes of this study; Pathway users were recruited primarily through banner advertisements and e-mails to members of the PatientsLikeMe health-based social networking site, offered a subsidized testing price (USD 25), and permitted to order PGT without physician mediation.

Data from consumers of both companies were collected via a series of 3 Web surveys administered by Survey Sciences Group (SSG; now SoundRocket), a third party survey research firm. Immediately after purchasing testing services, interested customers were brought to a Web page describing the study's purpose, assuring participants of data privacy and confidentiality, and inviting them to participate. After consenting, participants were able to access the study's baseline (BL) survey, which occurred after partici-

Public Health Genomics 2017;20:36-45 DOI: $10.1159 / 000455006$ 
Table 1. Overview of study measures and time of administration

\begin{tabular}{lllll}
\hline Study domain of interest & $\begin{array}{l}\text { Validated or } \\
\text { previously } \\
\text { published } \\
\text { measures/items? }\end{array}$ & & Time of administration & \\
\cline { 3 - 5 } & baseline & $\begin{array}{l}\text { 2- to 3-week } \\
\text { follow-up }\end{array}$ & $\begin{array}{l}\text { 6-month } \\
\text { follow-up }\end{array}$ \\
\hline Demographic characteristics & Yes & $\times$ & \\
Health-related information & Yes & $\times$ & \\
Test motivations and interests & No & $\times$ & \\
Test decision making considerations & No & $\times$ & \\
Perceived test utility & No & & \\
Decisional regret & Yes & & \\
\hline
\end{tabular}

pants had purchased testing but before they received test results. Within 2-3 weeks (2W) following receipt of their individual results, participants who said they had viewed their results were sent a follow-up survey asking about their reactions to PGT information. A third survey was administered at 6 months $(6 \mathrm{M})$ following consumers' receipt of PGT results. Institutional Review Boards at Brigham \& Women's Hospital and the University of Michigan reviewed and approved this study. As part of the informed consent process, participants agreed to the publication of aggregate survey data.

\section{Measures}

Overview

As noted above, the PGen Study involved a series of longitudinal surveys administered both before and after consumers learned their DTC-PGT results. An interdisciplinary team of academic and industry scientists developed a battery of measures to be used in the study, drawing upon expertise in disciplines including survey methodology, medical genetics, genetic counseling, health psychology, health services research, and medical decision making. Questionnaires incorporated both validated measures and novel survey items created specifically for the purposes of this study. Development of the latter included pilot testing in a small convenience sample of adults, with standard cognitive interviewing techniques used to inform modifications to question wording and response choices. The $\mathrm{BL}, 2 \mathrm{~W}$, and $6 \mathrm{M}$ surveys consisted of 240 , 77 , and 248 questions, respectively, with median response times across the surveys ranging from 22 to $32 \mathrm{~min}$. However, we report here on only a subset of the measures administered in the larger PGen Study, as summarized in Table 1 . The reader is referred to our previously published work for findings on other study outcomes including comprehension of test results [14], changes in disease risk perceptions [17], changes in prescription medication use [18], and use of primary care services following testing [19].

\section{Sociodemographic Information}

Demographic characteristics were ascertained using self-report items assessing age, gender, race/ethnicity, education level, employment status, and household income.

Health-Related Information

Self-rated health was assessed by a standard self-report item [20] asking participants to rate their health on a 5 -point scale $(1=$ poor to $5=$ excellent).
Body mass index (BMI) was assessed by using participants' selfreported height and weight to calculate a ratio based on standard criteria [21]. Based on their BMI score, participants were then classified as underweight (12.0-18.4), normal (18.5-24.9), overweight (25-29.9), or obese (30 or more).

Smoking status was assessed by asking participants if, and how often, they currently smoked cigarettes. Those endorsing the "some days" or "every day" response option were classified as current smokers.

Current screening practices were assessed by asking participants whether they had undergone various disease screening tests within the past year (and if not, whether they had ever undergone screening). Examples included mammography, colonoscopy, and prostate-specific antigen (PSA) tests.

Prior experience with genetic services was assessed by asking participants whether or not they had previously undergone genetic testing (other than newborn screening), met with a clinical genetics specialist, or purchased personal genomics services from another company.

Insurance status was assessed by asking participants whether or not they currently held health, life, disability, or long-term care insurance policies.

Test Motivations and Interests

Participants were asked at BL about their level of interest $(1=$ not at all interested, $2=$ somewhat interested, $3=$ very interested) in various types of genetic information provided by the 2 companies, including ancestry, disease risks, carrier screening, medication response, and trait information (this latter option was provided only by 23 andMe).

Participants were also asked about their level of interest $(1=$ not at all interested, 2 = somewhat interested, 3 = very interested) in learning about their genetic risk for numerous specific conditions provided in the companies' services. A composite measure of interest in disease-specific risks was created by summing responses to questions about 16 distinct conditions (range: 16-48, with higher scores indicating greater overall interest). Cronbach's a for this measure was 0.91 .

Decision Making

Participants were asked at $\mathrm{BL}$ about the extent to which they had considered $(1=$ did not consider, 2 = considered somewhat, $3=$ considered a lot) issues related to their decision to purchase
Roberts/Gornick/Carere/Uhlmann/ Ruffin/Green 
Table 2. Sample characteristics

\begin{tabular}{|c|c|c|c|c|}
\hline Characteristic & $\begin{array}{l}\text { Pathway Genomics } \\
(n=563)\end{array}$ & $\begin{array}{l}\text { 23andMe } \\
(n=1,085)\end{array}$ & $\begin{array}{l}\text { Total } \\
(n=1,648)\end{array}$ & $\begin{array}{l}\text { General } \\
\text { population } \\
\text { estimates }\end{array}$ \\
\hline \multicolumn{5}{|l|}{ Age, years } \\
\hline $18-34$ & $215(38.2 \%)$ & $261(24.1 \%)$ & $476(29 \%)$ & $30 \%$ \\
\hline $35-54$ & $219(38.9 \%)$ & $353(32.6 \%)$ & $572(34.7 \%)$ & $34.7 \%$ \\
\hline $55+$ & $129(22.9 \%)$ & $469(43.3 \%)$ & $598(36.3 \%)$ & $35.5 \%$ \\
\hline \multicolumn{5}{|l|}{ Gender } \\
\hline Female & $379(67.3 \%)$ & $616(56.8 \%)$ & $995(60.4 \%)$ & $51.4 \%$ \\
\hline \multicolumn{5}{|l|}{ Race/ethnicity } \\
\hline White & $513(91.1 \%)$ & $971(89.4 \%)$ & $1,484(90.0 \%)$ & $74.7 \%$ \\
\hline Hispanic/Latino & $32(5.7 \%)$ & $56(5.2 \%)$ & $88(5.4 \%)$ & $7.6 \%$ \\
\hline Black & $12(2.1 \%)$ & $54(5.0 \%)$ & $66(4.0 \%)$ & $7.6 \%$ \\
\hline Other & $6(1.1 \%)$ & $4(0.4 \%)$ & $10(0.6 \%)$ & $10.1 \%$ \\
\hline \multicolumn{5}{|l|}{ Education } \\
\hline Some college or below & $150(26.6 \%)$ & $213(19.8 \%)$ & $363(22.1 \%)$ & $73.4 \%$ \\
\hline College or greater & $413(73.4 \%)$ & $871(80.2 \%)$ & $1,284(77.9 \%)$ & $24.2 \%$ \\
\hline \multicolumn{5}{|l|}{ Employment status ${ }^{\mathrm{a}}$} \\
\hline Employed & $357(63.4 \%)$ & $670(61.8 \%)$ & $1,027(62.3 \%)$ & $48.9 \%$ \\
\hline Retired & $84(14.9 \%)$ & $257(23.7 \%)$ & $341(20.7 \%)$ & $17 \%$ \\
\hline Self-employed & $51(9.0 \%)$ & $101(9.4 \%)$ & $152(9.2 \%)$ & $8.3 \%$ \\
\hline Unemployed & $67(11.9 \%)$ & $41(3.8 \%)$ & $108(6.6 \%)$ & $7.4 \%$ \\
\hline Student & $57(10.1 \%)$ & $69(6.4 \%)$ & $126(7.6 \%)$ & $5.6 \%$ \\
\hline Household income, USD & & & & n.a. \\
\hline$<40,000$ & $140(25.1 \%)$ & $146(13.4 \%)$ & $266(16.3 \%)$ & \\
\hline $40,000-69,000$ & $100(17.9 \%)$ & $204(18.8)$ & $304(18.4 \%)$ & \\
\hline $70,000-99,000$ & $110(19.7 \%)$ & $215(19.8 \%)$ & $325(19.7 \%)$ & \\
\hline $100,000+$ & $208(37.3 \%)$ & $520(48.0 \%)$ & $728(44.2 \%)$ & \\
\hline \multicolumn{5}{|l|}{ Self-reported health } \\
\hline Good to excellent & $417(74.1 \%)$ & $984(90.9 \%)$ & $1,401(85.0 \%)$ & $83.1 \%$ \\
\hline Poor to fair & $146(25.9 \%)$ & $99(9.1 \%)$ & $245(14.9 \%)$ & $16.9 \%$ \\
\hline \multicolumn{5}{|l|}{ Body mass index } \\
\hline Underweight (12-18.4) & $13(2.3 \%)$ & $21(1.9 \%)$ & $34(2.1 \%)$ & $1.8 \%$ \\
\hline Normal $(18.5-24.9)$ & $259(46.6 \%)$ & $426(39.9 \%)$ & $685(42.2 \%)$ & $34.2 \%$ \\
\hline Overweight (25-29.9) & $141(25.4 \%)$ & $360(33.2 \%)$ & $501(30.8 \%)$ & $35.8 \%$ \\
\hline Obese $(30.0+)$ & $143(25.7 \%)$ & $262(25.0 \%)$ & $405(24.9 \%)$ & $27.6 \%$ \\
\hline Current smoker & $51(9.1 \%)$ & $65(6.0 \%)$ & $116(8.6 \%)$ & $19.6 \%$ \\
\hline \multicolumn{5}{|l|}{ Cancer screening } \\
\hline Mammogram (F 40+) & $225(59.4 \%)$ & $460(74.9 \%)$ & $685(69.0 \%)$ & $74.0 \%$ \\
\hline Colonoscopy (all 50+) & $222(89.9 \%)$ & $545(85.0 \%)$ & $767(86.6 \%)$ & $66.8 \%$ \\
\hline PSA test (M 40+) & $62(33.7 \%)$ & $228(48.8 \%)$ & $290(44.5)$ & $45.2 \%$ \\
\hline \multicolumn{5}{|l|}{ Insurance status } \\
\hline Health & $528(93.8 \%)$ & $1,033(95.2 \%)$ & $1,561(94.7 \%)$ & $79.6 \%$ \\
\hline Life & $325(57.9 \%)$ & $679(62.7 \%)$ & $1,004(61.0 \%)$ & n.a. \\
\hline Disability & $207(37.0 \%)$ & $428(39.8 \%)$ & $634(38.5 \%)$ & \\
\hline Long-term care & $91(16.3 \%)$ & $284(26.4 \%)$ & $375(22.7 \%)$ & \\
\hline
\end{tabular}

Some characteristics were assessed with slightly different survey items in the PGen versus BRFSS studies. For example, BRFSS classified as current smokers those who endorsed a "currently smoke" response, whereas in PGen current smokers were those who answered that they smoke cigarettes "some days" or "every day". Cancer screening was assessed in PGen by asking participants whether they had completed screening either "within the past year" or "more than a year ago"; in BRFSS, participants were asked about "within the past 2 years". For employment status, participants were given the response option of "unable to work" (6.1\%) on the BRFSS but not the PGen survey. F, female; M, male; PSA, prostate-specific antigen; n.a., not available. ${ }^{a}$ Participants could select more than one category. ${ }^{b}$ Based on 2012 nationwide estimates from the Behavioral Risk Factor Surveillance Survey (BRFSS). 
personal genomics services. Testing considerations included test cost, convenience, predictive value of test information, company education materials, available treatment options for conditions tested, information privacy, and the possibility of unwanted information. Participants were also asked if they had received PGT as a gift.

As part of the $6 \mathrm{M}$ survey, participants were administered a validated measure of decisional regret [22] assessing the extent to which respondents experienced regret or harm following their decision to pursue testing (range: $0-100$, with higher scores indicating greater levels of decisional regret). Cronbach's $\alpha$ for this measure was 0.87 .

Perceived Utility of Results

As part of the $2 \mathrm{~W}$ survey, participants were surveyed regarding their perceptions of the utility of services and satisfaction with information provided. Responded were asked to indicate their level of agreement $(1=$ strongly disagree to $5=$ strongly agree $)$ with 8 statements, with responses summed to create a composite measure (range: 8-40, with higher scores indicating greater perceived utility). Cronbach's a for this measure was 0.85 .

\section{Data Analyses}

Descriptive statistics characterized the sample in terms of its demographics, health-related experiences, and other questionnaire responses. Participants' demographic characteristics and health-related information were compared to data collected as part of the Behavioral Risk Factor Surveillance System (BRFSS), a nationwide surveillance system established by the Centers for Disease Control and Prevention [23]. Comparisons to the US general population were sought given that both the PGT companies and the vast majority of their consumers are based in the US.

Associations between demographic variables and outcomes of interest were examined using linear or logistic regression. Models included as their dependent variable either a composite outcome measure of interest (interest in disease-specific risks; perceived utility of results) or whether or not participants had reported "not at all" considering the possibility of unwanted information when deciding about testing. The following predictors were included in each regression model: age (categorized as $18-34,35-54$, or $\geq 55$ years old), gender, race/ethnicity (white vs. nonwhite), level of education ( $\leq$ high school or some college, college degree, or graduate degree), company (Pathway or 23andMe), and health status (good/ very good/excellent vs. fair/poor). A significance level of $p<0.05$ was used in analyses, which were conducted using SPSS statistical software version 21 .

\section{Results}

A total of 1,648 participants completed the BL survey, including 1,085 customers (65.8\%) from 23andMe and 563 (34.2\%) from Pathway. Of these, 1,046 completed the $2 \mathrm{~W}$ survey and 1,042 completed the $6 \mathrm{M}$ survey. Survey respondents from 23andMe were similar to the broader sample of 3,900 23andMe consumers invited to the study in terms of age $($ mean $=50.1 \pm 15.8$ vs. $51.0 \pm 15.9$ years $)$,
Table 3. Level of interest across types of personal genetic information

\begin{tabular}{|c|c|c|c|}
\hline \multirow[t]{2}{*}{$\begin{array}{l}\text { Type of } \\
\text { information }\end{array}$} & \multicolumn{3}{|c|}{$\begin{array}{l}\text { Responses, \% endorsing out of } \\
n=1,648\end{array}$} \\
\hline & $\begin{array}{l}\text { not } \\
\text { interested }\end{array}$ & $\begin{array}{l}\text { somewhat } \\
\text { interested }\end{array}$ & $\begin{array}{l}\text { very } \\
\text { interested }\end{array}$ \\
\hline \multicolumn{4}{|l|}{ General } \\
\hline Ancestry & 3.9 & 22.5 & 73.7 \\
\hline Traits $^{\mathrm{a}}$ & 2.3 & 25.5 & 72.2 \\
\hline Disease risk & 1.9 & 26.2 & 71.9 \\
\hline Drug response & 9.1 & 38.8 & 52.1 \\
\hline Carrier status & 43.0 & 26.1 & 30.9 \\
\hline \multicolumn{4}{|l|}{ Disease-specific risks } \\
\hline Alzheimer disease & 6.8 & 26.9 & 66.3 \\
\hline Arthritis & 16.9 & 42.0 & 41.1 \\
\hline Asthma & 31.1 & 39.2 & 29.7 \\
\hline Bipolar disorder & 25.9 & 36.4 & 37.7 \\
\hline \multicolumn{4}{|l|}{ Cancer } \\
\hline Breast & 5.8 & 27.3 & 66.9 \\
\hline Colon & 11.2 & 36.1 & 52.7 \\
\hline Lung & 18.8 & 38.8 & 42.4 \\
\hline Prostate & 6.1 & 33.9 & 59.9 \\
\hline Skin & 9.2 & 31.4 & 59.4 \\
\hline Diabetes & 10.7 & 33.9 & 55.3 \\
\hline Heart disease & 5.2 & 27.0 & 67.8 \\
\hline Kidney disease & 20.3 & 42.7 & 36.9 \\
\hline Macular degeneration & 12.8 & 37.8 & 49.4 \\
\hline Multiple sclerosis & 21.1 & 39.4 & 39.5 \\
\hline Obesity & 23.0 & 36.0 & 41.1 \\
\hline Parkinson disease & 16.3 & 38.5 & 45.2 \\
\hline
\end{tabular}

${ }^{\text {a }}$ Responses from 23andMe consumers only.

but our survey respondents were slightly more likely to be female ( 56.8 vs. $47.8 \%$; $p<0.0001$ ). Data were not available to compare Pathway survey invitees versus responders.

Table 2 summarizes participants' sociodemographic and health-related characteristics. In brief, the sample was largely middle aged (mean age $=47.8$ years, $\mathrm{SD}=$ $15.6)$, and a majority were white $(90.0 \%)$ and female (60.4\%). The median educational level was college graduate. Compared to the general US adult population, study participants were more likely to be white (90 vs. $74.7 \%$ ), female (60.4 vs. $51.4 \%$ ), and college educated (77.9 vs. $24.2 \%)$. The vast majority $(85.0 \%)$ reported good to excellent health, with 23andMe customers more likely than Pathway customers to endorse better health status (90.9 vs. $74.1 \%)$. Fewer than $15 \%(13.8 \%)$ reported prior genetic testing experience in the health-care system, but $10.3 \%$ had already purchased another type of personal ge-
40

Public Health Genomics 2017;20:36-45 DOI: $10.1159 / 000455006$
Roberts/Gornick/Carere/Uhlmann/ Ruffin/Green 
Table 4. Perceived utility of personal genomic testing results

\begin{tabular}{|c|c|c|c|c|c|}
\hline $\begin{array}{l}\text { Questionnaire items } \\
\text { ( } n=1,026 \text { with valid responses) }\end{array}$ & $\begin{array}{l}\text { Strongly } \\
\text { disagree }\end{array}$ & $\begin{array}{l}\text { Somewhat } \\
\text { disagree }\end{array}$ & $\begin{array}{l}\text { Neither } \\
\text { disagree/agree }\end{array}$ & $\begin{array}{l}\text { Somewhat } \\
\text { agree }\end{array}$ & $\begin{array}{l}\text { Strongly } \\
\text { agree }\end{array}$ \\
\hline I am confident in the quality \& accuracy of my results & 1.5 & 2.6 & 10.9 & 47.3 & 37.7 \\
\hline I feel that I got what I paid for & 1.8 & 3.1 & 11.5 & 31.2 & 52.3 \\
\hline The educational materials provided were adequate & 1.8 & 6.5 & 12.6 & 48.2 & 30.9 \\
\hline $\begin{array}{l}\text { Having personal genomic testing made me feel like I have more } \\
\text { control over my health }\end{array}$ & 6.4 & 7.8 & 20.0 & 44.6 & 21.2 \\
\hline I learned something to improve my health that I didn't know before & 6.9 & 12.1 & 20.0 & 36.6 & 24.4 \\
\hline $\begin{array}{l}\text { The information I received has influenced how I will manage my } \\
\text { health in the future }\end{array}$ & 7.5 & 7.9 & 25.2 & 42.2 & 17.2 \\
\hline What I learned can help reduce my chances of getting sick & 8.2 & 13.2 & 30.4 & 35.9 & 12.4 \\
\hline I am disappointed that my results did not tell me more information & 16.0 & 21.7 & 24.3 & 28.5 & 9.5 \\
\hline
\end{tabular}

Figures indicate percentages.

netic testing (e.g., ancestry testing). Compared to the general population, study participants were less likely to be overweight/obese (55.7 vs. 63.4\%) or current smokers (8.6 vs. $19.6 \%$ ), more likely to have health insurance ( 94.7 vs. $79.6 \%$ ), and more likely to have completed a colonoscopy ( 86.6 vs. $66.8 \%$; among respondents age 50 and above only).

Respondents' levels of interest in types of genetic information are reported in Table 3. The type of information that the most participants reported being "very interested" in was ancestry (73.7\%), followed closely by traits (72.2\%, only assessed among 23andMe consumers because Pathway did not provide such information) and disease risks (71.9\%). Significantly fewer participants reported being very interested in medication response $(52.1 \%)$ or carrier status information $(30.9 \%)$. Participants' levels of interest in various disease risks are also reported in Table 3, broken down by condition. The conditions about which most respondents said they were "very interested" in learning about their risk were (1) heart disease (67.8\%), (2) breast cancer (66.9\%; women only), and (3) Alzheimer disease (AD; 66.3\%). A majority of participants also reported being very interested in prostate cancer (59.9\%; men only), skin cancer (59.4\%), diabetes (55.3\%), and colon cancer (52.7\%).

In terms of testing considerations involved in participants' decision making, the only factor that a majority said they "considered a lot" was "whether there are healthrelated actions I can take as result of learning my information" (51.1\%). Approximately a fifth to a half of the sample said they "considered a lot" factors including the convenience of being tested at home (46.3\%), genetic privacy (39.8\%), predictive value of test results $(30.4 \%)$, cost of

User Responses to DTC Genetic Testing services $(29.8 \%)$, and the possibility they might receive unwanted information (20\%). A minority said they did "not at all" consider the possibility they might receive unwanted information (37.9\%), genetic privacy (20.8\%), or the predictive value of testing (19.5\%). A total of 121 participants $(7.3 \%)$ said they had received PGT services as a gift.

Overall, participants reported low levels of decisional regret (mean score $=7.9$ out of 100) at 6 months following receipt of PGT results. Over $93 \%$ of respondents indicated that getting tested was "the right decision" for them, with $94 \%$ saying they would make the same decision again. Overall, $2 \%$ of respondents indicated that they regretted their decision to pursue testing, with $1 \%$ saying the decision had done them harm.

Respondents' perceptions of the utility of their results are summarized in Table 4. A majority of respondents said that results made them feel more in control of their health $(65.8 \%)$, that they learned something new to improve their health $(61 \%)$, and that PGT information would influence how they will manage their health (59.4\%). However, $38 \%$ agreed that they were disappointed their test results did not tell them more.

Table 5 summarizes regression analyses of variables associated with main study outcomes. Interest in disease risk information was higher among women, individuals with poor to fair self-reported health, and Pathway consumers, with those with less than a college education expressing greater interest in disease risks than those with a professional degree or doctorate (all $p<0.01$ ). Variables associated with greater likelihood of having considered the possibility of unwanted information in test decision making were younger age, female gender, and higher lev-

Public Health Genomics 2017;20:36-45 DOI: $10.1159 / 000455006$ 
Table 5. Regression analyses examining correlates of personal genomic testing interest, decision making, and perceived utility of results

\begin{tabular}{|c|c|c|c|c|c|c|c|c|c|c|c|c|}
\hline \multirow[t]{2}{*}{ Participant characteristic } & \multicolumn{4}{|c|}{$\begin{array}{l}\text { Interest in information about } \\
\text { disease risks }\end{array}$} & \multicolumn{4}{|c|}{$\begin{array}{l}\text { Considered unwanted } \\
\text { information in decision to seek } \\
\text { testing }\end{array}$} & \multicolumn{4}{|c|}{ Perceived utility of results } \\
\hline & $\beta$ & SE & $t$ & $p$ value & OR & SE & $z$ & $p$ value & OR & SE & $t$ & $p$ value \\
\hline \multicolumn{13}{|l|}{ Age, years } \\
\hline $18-34$ & Ref. & Ref. & Ref. & Ref. & Ref. & Ref. & Ref. & Ref. & Ref. & Ref. & Ref. & Ref. \\
\hline $35-54$ & 0.44 & 0.31 & 1.43 & 0.154 & 0.75 & 0.10 & -2.14 & 0.032 & -0.06 & 0.16 & -0.38 & 0.707 \\
\hline$\geq 55$ & -0.16 & 0.31 & -0.50 & 0.619 & 0.45 & 0.06 & -5.75 & $<0.001$ & 0.28 & 0.16 & 1.75 & 0.081 \\
\hline Female & 1.14 & 0.25 & 4.54 & 0.001 & 1.46 & 0.15 & 3.50 & $<0.001$ & -0.57 & 0.12 & -0.45 & 0.191 \\
\hline White race & 0.00 & 0.41 & 0.00 & 0.996 & 0.76 & 0.13 & -2.47 & 0.124 & 0.17 & 0.22 & 0.78 & 0.437 \\
\hline \multicolumn{13}{|l|}{ Education } \\
\hline High school/some college & Ref. & Ref. & Ref. & Ref. & Ref. & Ref. & Ref. & Ref. & Ref. & Ref. & Ref. & Ref. \\
\hline College & -0.22 & 0.30 & -0.76 & 0.449 & 1.41 & 0.17 & 2.85 & 0.008 & 0.06 & 0.15 & 0.40 & 0.688 \\
\hline Doctoral/professional degree & -1.21 & 0.43 & -2.82 & 0.005 & 1.92 & 0.36 & 3.96 & 0.001 & 0.32 & 0.21 & 1.58 & 0.115 \\
\hline 23andMe company & -1.16 & 0.27 & -4.26 & $<0.001$ & 0.68 & 0.11 & -3.48 & 0.001 & 0.50 & 0.14 & 3.79 & 0.051 \\
\hline \multicolumn{13}{|l|}{ Health status } \\
\hline Fair/poor & Ref. & Ref. & Ref. & Ref. & Ref. & Ref. & Ref. & Ref. & Ref. & Ref. & Ref. & Ref. \\
\hline Good/very good/excellent & -1.20 & 0.35 & -3.39 & 0.001 & 1.15 & 0.08 & -3.21 & 0.784 & 0.14 & 0.18 & 9.21 & $<0.001$ \\
\hline
\end{tabular}

el of education (all $p<0.05$ ). Perceived utility of results did not differ significantly by key demographic variables, although those with poor to fair self-reported health reported lower levels of perceived utility than their counterparts with good to excellent self-reported health $(p<$ $0.001)$.

\section{Discussion}

We report here on findings from one of the largest surveys to date of DTC-PGT consumers. Study findings indicated that compared to the general US adult population, our sample was disproportionately female, white, and of higher socioeconomic status (SES). These findings are consistent with prior studies suggesting higher interest in DTC testing among these demographic groups [24, 25]. This sample also differed from the general US adult population on key health-related variables; study participants were more likely to possess health insurance, less likely to smoke, and less likely to be overweight or obese. These findings likely reflect participants' higher levels of SES and strong focus on health and wellness issues. However, it should also be noted that despite these distinctions, participants did not differ markedly from the general population in terms of certain self-reported health and cancer screening behaviors such as mammography and PSA testing.
As expected, most consumers indicated strong interest in learning about genetic risk information for medical conditions. Perhaps more notable was that consumers expressed approximately the same level of interest in genetic ancestry information and traits. This finding reflects the broad US population interest in genealogy, where several companies are marketing genetic testing to help individuals trace their ancestral history and link socially to distant relatives [26]. Consumers expressed lower levels of interest in pharmacogenomic (52\% very interested) and carrier testing information (31\%). This may be because these types of information are not always viewed as personally relevant (e.g., some consumers may not be taking prescription medications and/or may have aged beyond reproductive decision making), or because they are less familiar to consumers than other types of genetic tests.

Consumers expressed significant interest in learning their genetic risks for a wide range of medical conditions. The diseases of greatest interest tended to be common diseases (e.g., heart disease, breast cancer) with proven options for screening, treatment, and risk reduction via health behaviors. A notable exception was AD, where two-thirds of respondents said they were very interested in learning their risk. This level of interest is consistent with national surveys on public interest in genetic testing for AD [27]. Previous studies where APOE genetic test results have actually been disclosed to at-risk individuals suggest that testing is used to inform advance planning

Roberts/Gornick/Carere/Uhlmann/ Ruffin/Green 
(e.g., purchase of long-term care insurance) and engagement in health behaviors viewed by test recipients (if not proven by scientific research) as lessening the risk of $\mathrm{AD}$ and related health conditions $[28,29]$.

Our data on test decision making indicate that consumers considered a wide range of factors (e.g., convenience, types of information provided) before purchasing PGT services. However, these results also raise concerns that many decisions were made without full consideration of the potential risks and limitations of testing. For example, nearly $40 \%$ of respondents said they had not considered the possibility of unwanted information prior to purchasing PGT services. This result, along with the finding that $7 \%$ reported receiving PGT services as a gift, suggests challenges in obtaining fully informed consent to genetic testing in a DTC format. Consumers do provide consent upon purchase of services, but unlike in clinical practice, the process lacks a medical intermediary to discuss and highlight potential risks, which may include unanticipated disease risk results. One approach that has been suggested to address these concerns is a tiered approach to informed consent [30], where DTC test recipients are re-consented before potentially sensitive genetic results are disclosed. For example, 23andMe has used a format where its users are required to view educational materials before "unlocking" personal results that could indicate high risk of Parkinson disease (LRRK2 genotype), $\mathrm{AD}(A P O E)$, or hereditary breast or ovarian cancer $(B R C A$ $1 / 2$ ). Additional research is needed to understand quality of test decision making in a DTC format and to what extent consumers may be "blindsided" by genetic test information. It should be noted, however, that unanticipated and distressing DTC results may still yield medical benefits to test recipients and their family members [31].

In a November 2013 letter to 23andMe, the US FDA raised concerns about potential negative health consequences resulting from false positive or false negative assessments for high-risk indications. Particular concern was noted around $B R C A$ 1/2-related genetic risk for hereditary breast and ovarian cancer and certain drug responses (e.g., warfarin sensitivity). Only $2 \%$ of our respondents indicated that they regretted their decision to pursue testing, with $1 \%$ saying the decision had done them harm. However, the source of the regret or type of harms is unknown, suggesting the need for future research in this area. Given the relative rarity of $B R C A 1 / 2$ mutation carriers and active medication users with actionable pharmacogenomic results, particularly large sample sizes would be needed to assess the likelihood of the specific risks noted in the FDA letter.

User Responses to DTC Genetic Testing
Consumers' responses upon learning their PGT information suggest that they believed that test results would meaningfully inform their future health decisions and behaviors. Related findings from our work suggest that over a quarter of participants went on to share this information with their primary care physician [17], although it is unknown if and how PGT results influenced uptake of medical procedures and health outcomes. Despite this evidence that many consumers are already using or planning to use PGT results in guiding their health decisions, nearly $40 \%$ of respondents reported disappointment that their results were not more informative. Such unmet expectations appeared more likely among those reporting poor to fair health, a group that may have viewed PGT testing as a potential means of addressing or explaining their current health problems [32]. These results are consistent with emerging findings from the literature on clinical use of whole-genome sequencing, where many patients appear to overestimate the likelihood of benefit from current precision medicine approaches [33]. It may be that consumers are overrating the importance of genetic contributions to disease (vs. behavioral or environmental determinants) and/or that they presume current genetic testing technologies possess greater capabilities than they actually do.

This study possessed several strengths, including a large sample size and detailed assessment of participants who had purchased PGT from prominent providers in the field. However, this study also has notable limitations that should be kept in mind when interpreting results. All measures used were subject to potential self-report biases, and some questionnaire items had not been fully validated prior to their use. In addition, recruitment procedures (e.g., subsidized testing for Pathway customers) likely created selection biases such that findings may not fully generalize to the broader population of DTC-PGT users. The limited number of participants with lower levels of education and income (e.g., $84 \%$ of the sample reported an annual household income of USD 40,000 or above) makes it difficult to generalize these results to populations of low SES; future research in this area should attempt to enroll samples with greater diversity in terms of SES. Finally, detailed information was not available on certain outcomes of interest, such as specific genetic test information that participants found particularly useful and how exactly they planned to use such information to guide future health-care decision making and behaviors.

Many policy dilemmas continue to surround the provision of PGT in a DTC format, with much speculation

Public Health Genomics 2017;20:36-45 DOI: $10.1159 / 000455006$ 
about related risks and benefits, as well as debate over how to strike an appropriate balance between respecting individual consumer autonomy and protecting against potential harms. This study, conducted in a recent window of time in the US where access to DTC-PGT information was less constrained than at present, begins to provide insights on how consumers appraise and respond to genetic test information in this context. Our data suggest that consumers generally find PGT information useful and anticipate that it will be beneficial in guiding future health decisions, with very few consumers reporting harms or decisional regret. At the same time, our findings also suggest areas for improvement in the informed consent process for DTC-PGT, so that individuals undergoing testing recognize the potential for unwanted information and have realistic expectations regarding test benefits and limitations. Such findings could prove useful in guiding future practice and policy decisions in this area.

\section{Acknowledgements}

This study was funded by National Institutes of Health grant R01 HG005092.

Nonauthor members of the PGen Study team include the following: Sarah Kalia, Kurt Christensen, Harvard Medical School and Brigham and Women's Hospital; Mick Couper, Brent Doil, Lan Le, Jenny Ostergren, University of Michigan School of Public Health; Joanna Mountain, 23andMe; Glenn Braunstein, Pathway Genomics; Scott Crawford, Sound Rocket; Adrienne Cupples, Clara Chen, Catharine Wang, Boston University; Sarah Gollust, University of Minnesota; Stacy Gray, City of Hope Comprehensive Cancer Center; Kimberly Kaphingst, University of Utah; Barbara Koenig, University of California-San Francisco; Lisa Lehmann, US Department of Veterans Affairs; and Richard Sharp, Mayo Clinic.

\section{Disclosure Statement}

Dr. Green is compensated for speaking or advisory services from AIA, Helix, Illumina, Invitae, and Prudential. The other authors have no conflicts of interest to disclose.

\section{References}

1 Caulfield T, McGuire AL: Direct-to-consumer genetic testing: perceptions, problems, and policy responses. Annu Rev Med 2012;63:2333.

2 Vayena E: Direct-to-consumer genomics on the scales of autonomy. J Med Ethics 2015;41: 310-314.

3 Spencer DH, Lockwood C, Topol E, et al: Direct-to-consumer genetic testing: reliable or risky? Clin Chem 2011;57:1641-1644.

4 Hudson K, Javitt G, Burke W, Byers P; American Society of Human Genetics Social Issues C: ASHG Statement* on direct-to-consumer genetic testing in the United States. Obstet Gynecol 2007;110:1392-1395.

5 American College of Medical Genetics and Genomics: Direct-to-consumer genetic testing: a revised position statement of the American College of Medical Genetics and Genomics. Genet Med 2016;18:207-208.

6 National Society of Genetic Counselors: Direct access to genetic testing. 2015. http:// nsgc.org/p/bl/et/blogaid=370 (accessed August 17,2016 ).

7 US Food and Drug Administration DoHahS. 23andMe, Inc. 2013. http://www.fda.gov/ ICECI/EnforcementActions/WarningLetters/2013/ucm376296.htm (accessed August 17, 2016).

8 Annas GJ, Elias S: 23andMe and the FDA. N Engl J Med 2014;370:985-988.

9 Green RC, Farahany NA: Regulation: the FDA is overcautious on consumer genomics. Nature 2014;505:286-287.
10 Roberts JS, Ostergren J: Direct-to-consumer genetic testing and personal genomics services: a review of recent empirical studies. Curr Genet Med Rep 2013;1:182-200.

11 Bloss CS, Wineinger NE, Darst BF, Schork NJ, Topol EJ: Impact of direct-to-consumer genomic testing at long term follow-up. J Med Genet 2013;50:393-400.

12 Gray SW, Hornik RC, Schwartz IS, Armstrong K: The impact of risk information exposure on women's beliefs about direct-toconsumer genetic testing for BRCA mutations. Clin Genet 2012;81:29-37.

13 Egglestone C, Morris A, O'Brien A: Effect of direct-to-consumer genetic tests on health behaviour and anxiety: a survey of consumers and potential consumers. J Genet Couns 2013;22:565-575.

14 Ostergren JE, Gornick MC, Carere DA, et al: How well do customers of direct-to-consumer personal genomic testing services comprehend genetic test results? Findings from the impact of personal genomics study. Public Health Genomics 2015;18:216-224.

15 Carere DA, Kraft P, Kaphingst KA, Roberts JS, Green RC: Consumers report lower confidence in their genetics knowledge following direct-to-consumer personal genomic testing. Genet Med 2016;18:65-72.

16 Carere DA, Couper MP, Crawford SD, et al: Design, methods, and participant characteristics of the Impact of Personal Genomics (PGen) Study, a prospective cohort study of direct-to-consumer personal genomic testing customers. Genome Med 2014;6:96.
17 Krieger JL, Murray F, Roberts JS, Green RC: The impact of personal genomics on risk perceptions and medical decision-making. Nat Biotechnol 2016;34:912-918.

18 Carere DA, VanderWeele TJ, Vassy JL, et al: Prescription medication changes following direct-to-consumer personal genomic testing: findings from the Impact of Personal Genomics (PGen) Study. Genet Med, Epub ahead of print.

19 van der Wouden CH, Carere DA, Maitlandvan der Zee AH, et al: Consumer perceptions of interactions with primary care providers after direct-to-consumer personal genomic testing. Ann Intern Med 2016;164:513-522.

20 Ware JE Jr, Gandek B: Overview of the SF-36 Health Survey and the International Quality of Life Assessment (IQOLA) Project. J Clin Epidemiol 1998;51:903-912.

21 National Heart, Lung, and Blood Institute: BMI Calculator. http://www.nhlbi.nih.gov/ health/educational/lose_wt/BMI/bmicalc. htm (accessed August 17, 2016).

22 Brehaut JC, O'Connor AM, Wood TJ, et al: Validation of a decision regret scale. Med Decis Making 2003;23:281-292.

23 US Department of Health and Human Services, Centers for Disease Control and Prevention: Behavioral risk factor surveillance system survey data. Atlanta, US Department of Health and Human Services, Centers for Disease Control and Prevention, 2012. 
24 Bloss CS, Schork NJ, Topol EJ: Effect of direct-to-consumer genomewide profiling to assess disease risk. N Engl J Med 2011;364: 524-534.

25 Kaufman DJ, Bollinger JM, Dvoskin RL, Scott JA: Risky business: risk perception and the use of medical services among customers of DTC personal genetic testing. J Genet Couns 2012; 21:413-422.

26 Vence T: DNA ancestry for all. 2014. http:// www.the-scientist.com/?articles.view/articleNo/40460/title/DNA-Ancestry-for-All/ (accessed August 17, 2016).
27 Neumann PJ, Cohen JT, Hammitt JK, et al: Willingness-to-pay for predictive tests with no immediate treatment implications: a survey of US residents. Health Econ 2012;21: 238-251.

28 Roberts JS, Christensen KD, Green RC: Using Alzheimer's disease as a model for genetic risk disclosure: implications for personal genomics. Clin Genet 2011;80:407-414.

29 Christensen KD, Roberts JS, Whitehouse PJ, et al: Disclosing pleiotropic effects during genetic risk assessment for Alzheimer's disease: a randomized trial. Ann Intern Med 2016; 164:155-163

30 Bunnik EM, Janssens AC, Schermer MH: Informed consent in direct-to-consumer personal genome testing: the outline of a model between specific and generic consent. Bioethics 2014;28:343-351.
31 Francke U, Dijamco C, Kiefer AK, et al: Dealing with the unexpected: consumer responses to direct-access BRCA mutation testing. Peer] 2013;1:e8.

32 Meisel SF, Carere DA, Wardle J, et al: Explaining, not just predicting, drives interest in personal genomics. Genome Med 2015;7:74.

33 Roberts JS: Patients' understanding and expectations about use of next generation sequencing in oncology. Ann Behav Med 2015; 49(suppl 1):S70. 